\title{
Putting the Unbalanced Cart before the Horse: TESOL at Universities in China
}

\author{
${ }^{1}$ Li Yanying, ${ }^{1}$ Wang Yongmei, ${ }^{2}$ Guo Lijia \\ ${ }^{1}$ School of Foreign Languages for Economics and Trade Southwestern University of Finance \\ and Economics \\ ${ }^{2}$ School of Foreign Languages, University of Electronic Science and Technology of China
}

\begin{abstract}
TESOL in China has been embracing unprecedented opportunities as this country adopts opening-up and reform policies and propels TESOL in order to be better geared up for international participation and competition, but in the course of rapid development it has encountered major challenges. Although TESOL has promoted the cultivation of English talents, it has at the same time defaulted on its obligations to this country and the world at large: firstly, it places excessive emphasis on English culture at the sacrifice of ESL learners' competence to communicate Chinese culture to the rest of the world; secondly, TESOL in China is subject to the prevailing utilitarianism at the expense of humanistic care and moral edification. The authors argue that TESOL at universities in China has misplaced the cart before the horse through such default. And since it also fails to address the specific needs of ethnic minorities at universities, the "cart", namely English competence cultivation remains unbalanced. After identifying the unfulfilled obligations of TESOL practice at universities in China and analyzing its causes, this paper puts forward proposals to remedy the setbacks so as to improve Chinese ESL learners' cross-cultural communication capacity, contribute to their mental well-being and ethical integrity, as well as to empower the ethnic minority students to be in a better position to join globalization.
\end{abstract}

\section{Introduction}

Globalization demands the barrier-free communication among countries and regions, the difficulty to understand different languages and cultures is the first barrier to be removed so as to pave the way for dynamic interaction and harmonious co-existence of all nations. Since the implementation of opening-up and reform policies, China has taken gigantic strides in reaching out to the rest of the world and her foreign language education has been geared up to meeting the demands of increasingly frequent, broader and deeper international communication accordingly. TESOL (Teaching English to Speakers of Other Languages), as an indispensable part of the foreign language education system, has got a new lease on life ever since 1979, which marks a seismic change in the nation's prevalent attitudes towards the West especially those English-speaking countries. Such change can be characterized as from SHE (Suspicion, Hostility and Estrangement) to CAR (Curiosity, Admiration and Reservation). During the so-called Cultural Revolution, tuning in to BBC or VOA was tantamount to treason, but since the start of opening-up and reform, this has become daily routine for most English majors at universities or people who become English fanatics. TESOL ceases to be highly politicized and relentless efforts have been made by the education administration, teachers and researchers to improve the quality of TESOL in China with a view to turning out talents wellequipped with this prevalent global language to fulfill their duties in an increasingly interconnected world. However, our survey into the cultural content in TESOL among 268 university students shows its default on lecturing about Chinese culture, and the other survey among 122 university students reveals the insufficiency or absence of humanistic care and moral edification in China's TESOL. Meanwhile, the fact that students of 56 nationalities in China are largely subject to the uniformity of College English Curriculum Requirements has swept the ethnic differences and the ensuing varied demand under the carpet, and the shortage of ethnic TESOL teachers has hampered the effective improvement of English competence of the ethnic students due to the inadequate awareness of the specific demand of the ethnic students and the necessary knowledge and skills to meet such demand.

\section{Tesol Destitute of Chinese Culture}

TESOL in China needs to fulfill an obligation which it has neglected or ignored, namely, promoting Chinese culture.

\subsection{Problems revealed by a survey}

This survey about Chinese culture content in TESOL consists of 6 questions. The first question is: Do you think it's necessary for Chinese ESL (English as a Second Language) learners to be able to talk about Chinese culture in English? After rounding off, about $80 \%$ respondents chose: Yes, 
about $14 \%$ respondents chose: No, and $6 \%$ respondents chose: Uncertain. The second question is: Can you use English to talk about Chinese culture and the related issues? After rounding off, about $1 \%$ chose: Yes, and almost without any difficulty, about 48\% chose: Yes, but sometimes I would encounter some difficulty, about $44 \%$ chose: Uncertain, because I have a lot of difficulty, and about $7 \%$ chose: No, I can't. The third question is: Do you think English textbooks and other teaching materials should include Chinese culture content? After rounding off, about $80 \%$ chose: Yes, about $14 \%$ chose: No, and about $6 \%$ chose: Uncertain. The fourth question is: Is Chinese culture content included in your English teaching materials (both at middle school and university level)? After rounding off, about $7 \%$ chose: Yes, about $82 \%$ chose: No, and about $11 \%$ chose: Uncertain. The fifth question is: Do you think it's imperative for English teachers to lecture on Chinese culture in English? After rounding off, about $73 \%$ chose: Yes, about $15 \%$ chose: No, and about $12 \%$ chose: Uncertain. The sixth question is: Have your English teachers (both at middle school and university level) lectured on Chinese culture in English? After rounding off, about $15 \%$ chose: Yes, and often, about $76 \%$ chose: Yes, but occasionally, and $9 \%$ chose: No.

This survey shows that most of the respondents (80\%) wished to be able to talk about Chinese culture in English, but only a few of them (1\%) found no difficulty in doing so. This survey also shows that most of the respondents $(80 \%)$ thought it's necessary to include Chinese culture content into their English teaching materials but only very few of them $(7 \%)$ found Chinese culture content had been included into their English teaching materials. The majority of the respondents (73\%) thought it's imperative for English teachers to lecture on Chinese culture in English, but only some of them (15\%) found their teachers often lectured on Chinese culture in English. The sharp contrast between ESL learners' demand for the competence to communicate Chinese culture and their real capacity for meeting that demand, as well as that between the high expectation of Chinese culture as an indispensable part of TESOL content and the low satisfaction with the reality reveal it's high time for TESOL in China to choose the trajectory of reform and readjustment.

\subsection{Causes behind the problems}

A delve into China's modern history and her course of opening-up and reform may disclose certain causes leading to the phenomena. The implementation of opening-up and reform policies has shifted China from the isolated doldrums into a dramatically and incrementally receptive and inclusive status, especially after the end of the so- called Cultural Revolution which plunged the whole country into ten-year-long chaos. Given this background, Chinese people, on the threshold of a brand new world and driven by unprecedented curiosity and aspirations for a better life, had more than ever wished to learn those new things across the national boundaries, things from the West in particular. The awareness of the gap between China's comparatively backward scientific, technological and economic strength and that of the developed countries and the suppressed grudges as a result of the previous political campaigns had fueled the impulse of some Chinese to ditch everything about China and follow whatever popular in the West, which begets "Chong yang mei wai", meaning to worship things foreign and fawn on foreign countries. And such biased and uncritical attitudes had been adopted by some Chinese as they tried to seek silver bullet to cure the woes of this nation or their own life or both. One implication of such attitudes for TESOL in China is the over-emphasis on cultures of the English-speaking countries while ignoring the communication of Chinese culture.

\subsection{Impact as a result of such problems}

Kramsch [1] points out that until recently the pedagogy of English as a second language was unabashedly acculturationist, indeed, assimilationist. It taught immigrants mainstream middle-class American or British ways of speaking, thinking and behaving in everyday life. Unfortunately, what is happening to TESOL in China nowadays echoes the concern about acculturation and assimilation.

TESOL is the pivotal approach to assist ESL learners with their cross-cultural communication, and since such communication is not and should not be a one-way process but rather a two-way interaction, TESOL deprived of the content of those ESL learners' native culture cannot function soundly in bridging the cultural gap. Communication in the process of globalization is not just about "taking in", but also about "giving out", for any nation that wishes to maintain her identity and have her voice heard in the international community, to disseminate is as important as to assimilate. Be it in the arena of diplomatic or non-governmental exchanges, the competence of giving utterance to one's own culture is equally significant as that of understanding the foreign culture. In the process of globalization, TESOL places disproportionate emphasis on the acquisition of English culture and destitute of the effort to sensitize ESL learners to their own culture and empower them to communicate their own culture to the rest of the world is destined to blur their national identity and dilute their national values. Solís-Gadea [2] points out: It has become essential to provide human beings with an education that would allow them to understand themselves as individuals 
but also as a part of a common order which connects them all and turns them into citizens of the world, without letting out of sight their own identity and national values.

\subsection{Countermeasures to address the problems}

As a nation with over 5000 years' history, China boasts rich and profound cultural heritage and diversified folk customs, the quintessence of which is worthy of being appreciated by the rest of the world. It would be a great loss both to China and the rest of the world if in cross-cultural communication such quintessence of civilization cannot be noted and shared due to the incompetence of the ESL learners. To guard against such loss, countermeasures must be taken not only to boost the TESOL practitioners' awareness of Chinese culture in a top-down approach starting from the educational administration level but also to sensitize the ESL learners to the urgency of being able to introduce and elaborate on Chinese culture following a bottom-up approach promoted by the TESOL practitioners. Chinese culture content needs to be included in the teaching materials of TESOL and the related topics should be discussed in TESOL class.

\section{Tesol short in humanistic care and moral edification}

TESOL in China inclines to skill training instead of an integrated approach to fulfill the obligations of humanistic care and moral edification.

\subsection{Problems revealed by a survey}

The second concern about TESOL in China is the neglect of humanistic care and moral edification.

We conducted the other survey to find out the expectation and reality of humanistic care and moral edification of TESOL in China. A total of 122 students from 9 universities filled the questionnaires. The first question is: Besides the training in linguistic skills, do you think TESOL should also perform the function of humanistic care (such as inspiring students with a positive attitude towards life, appealing to the good qualities in students)? After rounding off, about $83 \%$ respondents chose: Yes, about $9 \%$ respondents chose: No, and about $8 \%$ chose: Uncertain. The second question is: Has the TESOL (both at middle school and university level) you received performed such function? After rounding off, about $30 \%$ chose: Yes, and often, about $39 \%$ chose: Yes, but not often, and about $31 \%$ chose: No. The third question is: Do you wish to see in English class, the students' reports and remarks with views reflecting qualities like integrity and sympathy can be appreciated and encouraged by the teachers just because of the views themselves? After rounding off, about $87 \%$ chose: Yes, about $3 \%$ chose: No, and about $10 \%$ chose: Uncertain. The fourth question is: Have your English teachers given such appreciation and encouragement? After rounding off, about 39\% chose: Most of my teachers do, about $30 \%$ chose: Some of my teachers do, and $31 \%$ chose: No. The fifth question is: Do you hope your English teachers discuss with students in class issues related to people's concerns in China (For instance, the scandal of contaminated baby formula)? After rounding off, about $94 \%$ chose: Yes, about $2 \%$ chose: No, and about $4 \%$ chose: Uncertain. The sixth question is: Have your English teachers discussed the abovementioned issues in class? After rounding off, about $21 \%$ chose: Most of my teachers do, about $21 \%$ chose: Some of my teachers do, and about $58 \%$ chose: No. The seventh question is: Do you hope your English teachers promote some universal values (such as justice, equality, protecting the environment)? After rounding off, about $86 \%$ chose: Yes, about $6 \%$ chose: No, and about $8 \%$ chose: Uncertain. The eighth question is: Have your English teachers promoted some universal values in class? After rounding off, about $32 \%$ chose: Most of my teachers do, about $52 \%$ chose: Some of my teachers do, and about $16 \%$ chose: No.

This survey shows that most of the respondents (83\%) thought TESOL should deliver humanistic care but only some of them (30\%) found the TESOL they received performed that duty often. Most of the respondents (87\%) wanted the English teachers to appreciate and encourage in class students' remarks reflecting qualities like integrity and compassion, but only some of them (39\%) found most of their English teachers did that. Most of the respondents (94\%) wished their English teachers to discuss issues related to people's concerns in China, but only some of them $(21 \%)$ said that most of their English teachers did that. Most of the respondents (86\%) hoped their English teachers can promote some universal values, but only some of them (32\%) found most of their English teachers did that. The discrepancy between the students' wishes for humanistic care and moral edification of TESOL and the disappointing reality they found urges the educational administration, TESOL practitioners and researchers to focus more on the underestimated, debilitated or even ignored functions of TESOL.

\subsection{Causes behind the problems}

In China, English is more often than not viewed as core competitiveness in vying for job opportunities, academic or professional promotion, or even a passport to the West. Those who excel at English stand better chances for success in academic or social competition, and such reality spurs people 
to strive hard for the mastery of English. The frenzy for English capacity has inclined TESOL to be skillobsessed and exam-oriented. To enable ESL learners to have a good command of English and score high in academic or aptitude tests has become the benchmark for success in most TESOL institutes around China. Not long ago, passing CET 4 (College English Test Band 4) had been the precondition for graduates at most of China's universities and colleges to be conferred upon the bachelor's degrees, many graduates were therefore denied their first jobs because of the delay or denial of the academic degrees. It had almost been a conversational taboo among most young Chinese graduates who had been tormented and haunted by CET 4 . Some tragedies occurred where the graduates went to such an extreme by committing suicide after the failure in CET 4 and concomitantly in hunting for their desirable jobs. Later, with the growing humane concern and fear for lowered employment rate, most Chinese universities and colleges had canceled the links between CET 4 and academic degree conferment, but the removal of such requirement can do little for changing the utilitarianism in TESOL.

\subsection{The necessity of solving such problems}

Every year, a profusion of conferences have been held on TESOL and myriads of dissertations have been published discussing TESOL in China at all levels. Despite all the input into the research and teaching practice, if the educational administration, scholars and teachers fail to see it as the obligations of TESOL to deliver humanistic care and moral edification, TESOL in China is likely to be bogged down in a morass of technical details without going where the education of humanities should go, namely, to educate people not only for high intelligence but also for sound personality and high morality.

China, despite her leapfrog economic development, is in the throes of individuals' psychological crises and the society's moral crises. According to the 2009 statistics released by the National Center for Mental Health, China had as many as 100 million mentally ill people, including more than 16 million who suffer from serious conditions. That means one out of 13 people were mentally disturbed and one out of 100 were seriously ill [3]. And the food security scandals keep cropping up, reflecting the moral decadence of the stakeholders in the profit chain and the nonfeasance or even malfeasance of the regulatory body. To curb and reverse such negative trend, education of humanities as a whole, has an unshakable responsibility to perform so as to help both the individuals and the society tide over the crises through cultivating in people the right sense for themselves and for others. TESOL, as an indispensable part of China's education of humanities, should cease to see itself merely as an English language and culture training system and therefore abdicate its obligations of humanistic care and moral edification.

\subsection{Countermeasures to address such problems}

It is high time TESOL in China shared responsibility and contributed to the students' mental and ethical integrity and the first step is to appeal to those good qualities in human nature, such as honesty, rectitude, self-discipline, self-esteem, tolerance, sympathy, optimism, enthusiasm, diligence, etc. In addition to that, as is required for each citizen in this global village, it should also help promote those universal values, such as justice, freedom, democracy, protecting the environment, etc.

As for the approaches to this end, first of all, efforts should be made to advance the guiding principles of TESOL practice, most likely in the form of English curriculum requirements at different levels. In addition to supplementing with the ignored Chinese culture awareness and content, remedies should also include adding the humanistic care and moral edification to the list. The requirements should make it explicit that TESOL in China delivers positive thought and rightful values in a bid to guide the students to develop their personality and ethics. Since the definitions of rightful values vary according to different ideology or religion people hold, it is necessary to note that rightful values in this case equal universal values, namely, values that can withstand the test of time and are still shared by the largest number of people across the widest territory, and have generated and will continue to generate positive and far-reaching influence on mankind.

Among others, environmental protection is no longer a fringe issue in today's world that witnessed increasingly frequent extreme weather and ecological deterioration, for both of which mankind are to be hold accountable. Given the urgent and tough environmental challenges such as climate change, depletion of natural resources and extinction of species, respect for Mother Nature is the part and parcel of universal values that should be upheld and popularized by education, and TESOL, as a branch of education of humanities, has a significant role to play.

Secondly, efforts should be made to improve the content of TESOL, mostly in the form of teaching materials. More content that can inspire students with positive thought and guide them to develop rightful values must be included in the textbooks, audio-visual materials and supplementary reading. TESOL in China should refrain from the obsession about skills; instead, it should devote more to the 
cultivation of students' personality and ethics. Such cultivation is not contradictory to the demands of the society for talents with cross-cultural communication skills because the training in communication skills should be content-based, and the key lies in the wellchosen content that can deliver the correct notions. This does not mean that the exposition of science and technology or other ESP (English for Special Purposes) content should be excluded from the teaching materials, however, content such as reports and stories based on facts that can be inspiring, thought-provoking, and edifying stand a better chance of guiding students in the right direction. It is almost impossible to quantify the influence of a piece of article or an audio-visual clip on a person, but it is undeniable that the seemingly trivial materials sometimes can generate formative effect on students' personality.

Thirdly, it's the responsibility of the TESOL practitioners in China to be careful with the way of delivering the content. They should adopt an unbiased and respectful attitude so as not to impose anything on the students nor offend the students through denying or even denouncing their thought and ideas. A cooperative and democratic atmosphere needs to be fostered in TESOL class, which is no easy task for TESOL practitioners in a country where the absolute loyalty and obedience to the teachers have long been formed in students' mentality. In a cooperative and democratic atmosphere, teachers should guide the students to see beyond the immediate interest of themselves and expose them more frequently to issues concerning others' wellbeing and the society as a whole, and through encouraging free exchange of views, incline them to be more sympathetic, empathetic and accommodating. While in organizing the in-class discussions, teachers should keep detached from any political or religious stance or disposition and refrain from showing idiosyncrasies in order to remain an impartial organizer and coordinator in the process of discussion. Students' views reflecting moral virtues or their upholding of the universal values should be appreciated and encouraged by the teachers without the opposite views denounced.

\section{TESOL still unbalanced despite progress}

To be single-minded in pursuing the students' English competence, neglecting or ignoring the communication of Chinese culture as well as humanistic care and moral edification can be equated with putting the cart before the horse. However, the cart, namely to cultivate and improve the students' English competence remains largely unbalanced due to the national uniformity based on the disregard for ethnic differences in TESOL guiding principles and practice despite the fact that much has been done to strengthen the students' practical skills in crosscultural communication during the evolvement of TESOL at universities.

\subsection{The progress of TESOL: being more practice-oriented}

It has long been a cliché among Chinese people to say that most of the English learners in China have acquired "deaf" and "mute" English, referring to the fact that most of Chinese English learners cannot meet the practical demand for listening and speaking skills in cross-cultural communication. And this fact is obviously an indictment of the TESOL pedagogy that has been subject to the baton of national standards issued by the Department of Higher Education of the Ministry of Education in China. However, with China's international communication gaining momentum, the dire need for practical English skills especially listening and speaking have urged the education authority to dictate a change. The situation seems to be turning around with the two rounds of revamps in College English Curriculum Requirements that occurred in 1999 and 2007 respectively. Each revamp can be regarded as the response and anticipation of the society's demand for competent English users. For instance, in the College English Curriculum Requirements issued in 2007, three years after the implementation of its trial version, the core emphasis has been placed on the cultivation of students' comprehensive English abilities in application, especially listening and speaking, in order to, as it claims, enable the students to communicate effectively in their study, work and social networking by using English, and at the same time, to enhance their abilities of independent, selfreliant study, as well as to heighten their comprehensive cultural qualities for meeting the requirements of social development and international exchanges [4]. A noteworthy change is the proposition of a computer-based TESOL mode as an important assistance to the conventional teaching mode. In the new requirements, TESOL setting consists of two parts: the teacher-to-students setting and the computer and internet-based setting. Both of them are responsible for the five categories of skills training: listening, speaking, reading, writing and translation. Nevertheless, each of them has prioritized certain skills: the conventional teacher-tostudents mode focuses on speaking, reading, writing and translation while the computer and internetbased one focuses on listening, speaking and reading. TESOL teachers are supposed to participate not only in the teacher-to-students mode but also in the computer and internet-based mode, while in the former one they must be present in person, in the later they can participate through interacting with their students on line. What merits our attention is that the role of TESOL teachers in both of the two 
settings has been defined as the organizer of the teaching and learning in contrast to what's in the previous scenarios: the controller of the teaching and learning. According to the requirements [5], the new teaching mode is expected to reflect the principles of being practical, informative and interesting and to motivate as much as possible both the teachers and the students.

Another positive and equally significant change has taken place in the reform of CET 4 and CET 6 (College English Test Band 6, which is more advanced than CET 4). Since the first CET 4 was held in 1987 and CET 6 in 1989, the scale of both tests keep expanding, and to date, around 10 million people sit the exams annually [6]. As national English aptitude tests, CET 4 and CET 6 have been adopted by many prospective employers in China as a benchmark for estimating the English abilities of their job candidates. But to the dismay of the employers, the certificates of CET 4 and CET 6 cannot attest to the employees' English abilities required for practical purposes in the workplace. And to the chagrin of the employees, their aptitudes warranted by CET 4 and CET 6 seem unsuitable for the cross-cultural communication at work. Such realization has propelled the reform of the tests. Since 1999, CET Spoken English Test has been implemented in some big cities in China, now it has been adopted by most of CET test centers, students who reach the stipulated scores are qualified to take the CET Spoken English Test. Since 2005, the full score of CET 4 and CET 6 has been changed from 100 points to 710 points, and instead of conferring certificates on those who score 60 points and above, transcripts would be issued to those who score 220 points and above, and no certificates would be further conferred. Through the reform, the makeup of the points has been readjusted to accentuate students' listening comprehension and translation abilities. The reforms of College English Curriculum Requirements and CET 4 and CET 6 have guided TESOL to be practice-oriented, and therefore English learners in China can acquire more marketable skills before starting work.

Another progress in TESOL is that many universities and colleges in China have adopted the module-based teaching where English lesson has been classified into different modules such as listening, speaking, writing, reading and translation. Students can opt for certain modules of their own volition. The introduction of module-based teaching aims to provide students with more flexible choices for efficient study. In addition to that, at some universities in China, English course becomes selective after students get the academic credits required or pass CET 4.

\subsection{TESOL unbalanced due to uniformity}

Due to historical, geographical, cultural and social reasons, the development levels of China's 56 nationalities are uneven, and disparities can be found between Han people and some ethnic minorities in terms of economic, cultural and educational conditions. Most Han students start to learn English in primary schools or even kindergartens, but for minority students living in remote and backward areas of China, English courses are not available until junior high schools, some start at senior high schools. For ethnic minority students, Chinese is their second language and English is the third language. In the learning process, they not only face the negative transfer of their mother tongue, but also that of Chinese. And since many ethnic minorities live in the mountainous areas of China, their access to the information about the West has been hindered by the comparatively backward environment where both qualified TEOSL teachers, audio-visual equipment and English magazines and newspapers are not available, therefore compared with their Han peers those ethnic minority students have more difficulties in learning English. Given the different starting levels, learning environment, learning capacity which is the consequence of both the learning environment and ethnic characteristics, TESOL targeting ethnic minority students at universities in China should not be subject to the unified standards and requirements. However, the ethnic differences are not addressed either in College English Curriculum Requirements or the requirements for CET 4 and CET 6. Students of ethnic minorities are studying under the same guiding principles as stipulated in the College English Curriculum, using the same English textbooks just like their Han counterparts, and the overwhelming majority of TESOL teachers at universities and colleges in China are of Han nationality. In most cases, the Han teachers are not conversant in the mother tongues of their ethnic minority students and if they do not try to acquaint themselves with the characteristics of the ethnic languages, they would have no idea about the challenges of their ethnic students in English learning and therefore cannot come up with proper solutions. For example, in the language of Zhuang, there is no phonetic stress in words, while in the language of Uygur, the stress always lies in the last syllables of words.

\subsection{Countermeasures to gain balance}

To redress the balance of the "cart", TESOL in China needs to scrutinize and attend to the ethnic differences of the English learners. Firstly, both government and educational administration should devote more resources to the training of TESOL 
teachers among ethnic minorities and to the compilation of TESOL textbooks for ethnic minorities. As Beverly Daniel Tatum [7] highlights the fact that as many educational institutions struggle to become more multicultural in terms of their students, faculty and staff, they also begin to examine issues of cultural representation within their curriculum. In China, besides employing native speakers as TESOL teachers and using textbooks written only in English at advanced level, to designate ethnic teachers to teach English learners of the same nationality and to let the ethnic students use English textbooks written in both their own languages and English can facilitate their English learning.

Secondly, Ethnic students should not be subject to the uniform standards of TESOL. As national guiding principles of TESOL at university level, the College English Curriculum Requirements and requirements for CET 4 and CET 6 should be revised to reflect the ethnic differences of China's English learners.

\section{Conclusion}

TESOL in China has gained momentum since the implementation of opening-up and reform policies in 1979, however, in its development; overwhelming importance has been attached to the assimilation of English linguistic skills and English culture at the sacrifice of students' competence to disseminating Chinese culture in English. Such imbalance in assimilating and dissimilating is likely to hinder China's international communication in the sense that the quintessence of Chinese culture cannot be appreciated and the condition of China cannot be accurately informed about due to the incompetence of ESL learners. To retrieve this situation, Chinese culture awareness should be raised among the TESOL administrators, practitioners and ESL learners, with teaching materials taking in content about China and Chinese culture and class interaction including the discussion about topics alike. In addition to that, attention also needs to be paid to its obligations of humanistic care and moral edification in China where TESOL has long been plagued by extreme utilitarianism. Countermeasures should be made to redress the balance through firstly stipulating in the curriculum requirements at different levels that it is the obligations of TESOL to edify students for sound personality and high moral standards, then include in the teaching materials the content that serves such purpose, and entrust TESOL practitioners with the teaching tasks not only dissimilating linguistic and cultural knowledge but also cultivating students' personality and promoting the universal values. Meanwhile, despite the progress in priming students for cross-cultural communication practice, TESOL has been unbalanced in improving students' English competence as a result of the negligence in ethnic differences, countermeasures to redress the balance include allocating more resources to train ethnic TESOL teachers and to compile English textbooks tailored to the needs of ethnic students. Uniformity should be removed from the national TESOL standards and special requirements need to be stipulated for the ethnic students at universities in China.

\section{References}

[1] Kramsch, C., "Culture in Language Teaching", Encyclopedia of Language \& Linguistics, Elsevier, London, 2006, pp. 322-329.

[2] Solís-Gadea, H. R., (2011) 'Education for Global Citizenship: The Role of Universities in the Maintenance of Civilization in the Context of Late Modernity and Globalization Some Comments on the Mexican Case', SCOPUS, http://www.scopus.com(3 October 2011).

[3] Yin Pumin, "A Mental Challenge, New Law in the Works to Improve Care for Mentally Ill Persons", Beijing Review, China International Publishing Group, Beijing, 2011, pp. 18-19.

[4] The Department of Higher Education of the Ministry of Education, "College English Curriculum Requirements", Foreign Language Teaching and Research Press, Beijing, 2007, pp. 1.

[5] The Department of Higher Education of the Ministry of Education, "College English Curriculum Requirements", Foreign Language Teaching and Research Press, Beijing, 2007, pp. 5.

[6] Yin Xiaoyong, (2012) 'Analysis of Reform of Question Types of CET-46 and the English Teaching Reform', China Academic Journal Electronic Publishing House, http://www.cnki.net (5 August 2012).

[7] Beverly Daniel Tatum, "Talking about race, learning about racism, the application of racial identity development theory in the classroom", Education for a multicultural society, Harvard. 